\title{
Relaciones entre cultura política y pobreza urbana: las alternativas de la política social
}

\author{
Rosalía López Paniagua y \\ Gerardo Torres Salcido \\ CIICH-UNAM
}

\begin{abstract}
Análisis de las relaciones entre la cultura política y la pobreza urbana. Se enfatiza el papel del acceso a los servicios básicos en las opiniones políticas y las formas

de gestión social, y se exploran las tendencias de la política social y sus relaciones con el poder presidencial, visto como un obstáculo para una cultura política democrática.
\end{abstract}

\section{INTRODUCCIÓN}

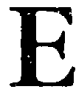

n este trabajo se analizan las relaciones entre la cultura política y la pobreza urbana a partir de resultados de una investigación realizada en la ciudad de México y el ărea conurbada, con el objetivo de plantear algunas alternativas de intervención estatal para el bienestar social en el marco de la transición neoliberal que vive el país. El análisis sobre estas relaciones enfatiza el papel del acceso a los servicios básicos en las opiniones políticas y las formas de gestión social como proceso de socialización y con- formación de identidades expresadas en la cultura política de los grupos pobres. En este sentido, buscamos rebasar las concepciones clásicas de la cultura política que ponen a ésta en el nivel subjetivo y la suponen un ámbito separado de las esferas de la economía y de la historia, perspectiva que ha orientado a la mayoría de estudios sobre cultura política en México. Para conseguirlo, en la primera parte revisamos los conceptos de cultura política y pobreza abordados en los estudios clásicos de la sociología política para el caso de los grupos pobres urbanos en México. Enseguida nos referi- 
mos a las características de los espacios urbanos y las formas de organización social que examina el estudio, como elementos de socialización politica en la consecusión de vivienda y subsidios alimenticios. Finalmente, incluimos los resultados de las opiniones de los integrantes de los hogares entrevistados que hacen referencia a la legitimidad de la política social, en relación a: la organización, el grado de confianza en las elecciones y sus opiniones sobre las autoridades locales; el presidente de la república y el Programa Nacional de Solidaridad. A manera de conclusión se exploran algunas de las tendencias e impactos de las actuales acciones gubernamentales en materia de política social y sus relaciones con el poder presidencial, identifícado como uno de los obstáculos para el desarrollo de una cultura política democrática y ciudadana.

\section{CULTURA POLÍTICA, POBREZA Y LEGITIMIDAD}

La noción de cultura política tal y como ha sido desarrollada en la sociología política mexicana, surge de los conceptos dados por el estudio pionero de Almond y Verba,${ }^{1}$ quienes concibieron la cultura política como una esfera separada de los campos de acción de la economía y la sociedad. Para ellos, la cultura política se define co-

' El debate se centraba en la incompatibilidad entre los fines institucionales y las aspiraciones individuales en los sistemas democráticos, esto es, una disparidad entre los fines del sistema cultural y los de la personalidad. Almond y Verba, Civic, 1963. El tema fue tratado nueva. mente en ibid., 1980. mo el conjunto de actitudes, normas, orientaciones y evaluaciones que se dirigen hacia el sistema político en sentido cívico.

A pesar de que algunas visiones recientes de la cultura política mexicana, en general, no han superado la perspectiva generalizadora y ahistórica del estudio de Almond y Verba ${ }^{2}$ el análisis de los procesos de socialización y de la forma en que se adquiere la experiencia política puede dar pautas para crear un concepto más amplio de cultura política, que comprenda las particularidades de ésta en los contextos nacional y regional. En este sentido, pensamos que un factor importante en el análisis de la cultura política de estos sectores, es la experiencia de socialización política al participar en la gestión, demanda y movilización que realizan para conseguir los servicios básicos para una colonia popular, cómo invadir un terreno, obtener crédito para la vivienda, instalar una lechería Conasupo-Liconsa u obtener tortibonos. Todas estas experiencias son en cierto modo distintas a las expresadas por el concepto tradicional de cultura democrática, entendida en el sentido anglosajón, y no coinciden necesariamente con una cultura electoral. Es importante considerar que en estos procesos de socialización, las organizaciones son una instancia de mediación entre los individuos y los niveles más altos del sistema político. ${ }^{3}$

${ }^{2}$ Gutiérrez, "Algunas", 1990, pp. 141-153. Un balance actual sobre el tema de cultura poli. tica puede verse en: Guadarrama, "Democracia", 1994, pp. 265-280.

${ }^{3} \mathrm{El}$ concepto tradicional de cultura política ha privilegiado las evaluaciones y percepciones 
Estos procesos de socialización admiten una doble lectura: por un lado fomentan la participación, las redes de solidaridad y los sentimientos de liberación, de tolerancia y de construcción de identidades; ${ }^{4}$ pero por otro lado tienden a reproducir los esquemas de liderazgos y poderes locales y centralizadores típicos de la cultura política nacional.

Los rasgos contradictorios de estos procesos pueden ser contrastados empíricamente en la cultura política y organizativa de los grupos pobres de la ciudad de México. Estos han sido estudiados por Cornelius, Lomnitz y Eckstein. ${ }^{5}$ Los rasgos que destacan estos autores son los vinculados con el autoritarismo, la cooptación clientelar y la conformación de redes solidarias y familiares para la supervivencia. En cuanto al clientelismo, estos autores han enfatizado el papel que el Partido Revolucionario Institucional (PRI) jugó al prometer la dotación de servicios básicos y de vivienda para los grupos inmigratorios recién llegados a la ciudad de México, constituyendo organizaciones y redes de soporte para las políticas oficiales. La legitimidad, es decir, la aceptación y obediencia de

de los individuos respecto a sus autoridades, $\sin$ considerar el papel que juegan las organizaciones sociales en la formación de aquéllas.

${ }^{4}$ La construcción de identidades como un proceso que se da en la participación en los movimientos sociales, en contraposición a una identidad fija y ontológica ("nacional" o "proletaria"), ha sido trabajada ampliamente por Melucci y coincide con lo que nosotros definimos como socialización de las experiencias. Véase Melucci, "Liberation", 1992, pp. 43-77.

5 Véase Cornelius, Migrantes, 1980, Lomnitz, Sobreviven, 1977, Eckstein, Estado, 1982. los pobres al régimen, fue en gran medida construida no con base en una aceptación consensual del mismo, lo que habría supuesto el desarrollo de una condición de ciudadanía y un incremento de la ilustración, sino que por el contrario, supuso la construcción de formas patrimoniales y/o corporativas que impusieron una visión tutelar a los ciudadanos, específicamente de aquéllos considerados pobres, con base en un entramado de relaciones para el acceso a subsidios y en una política social proclive a distribuirlos a través de instituciones plenamente identificadas con el régimen.

En cuanto a las redes de solidaridad y apoyo, los estudios antropológicos de Lomnitz demostraron que éstas corresponden a formas de vida campesina que se trasladaron con los migrantes a los barrios marginados 6 de la ciudad de México. Estas tradiciones no estaban alejadas de formas de dominación y organización tradicionales, basadas en un miembro de la familia o de la comunidad, que en los hechos actúa como jefe. Estas tradiciones representan un elemento de los entramados corporativos o partidarios que dieron legitimidad al régimen posrevolucionario, pero también fueron la base de formas de socialización, de autogestión y de aportación de trabajo colectivo para las organizaciones o los habitantes que por una $u$ otra razón, a pesar incluso de pertene-

\footnotetext{
${ }^{6}$ El concepto de marginación se refiere aquí a la localización de las colonias y a su carencia de servicios, pero se deslinda de los conceptos típicos marginalistas que veían a los pobres como carentes de toda posibilidad de integración a la moderna economía capitalista.
} 
cer oficialmente al PRI, no conseguían de manera expedita los servicios.

El desarrollo urbano del México posrevolucionario se fundamentó en establecer una legitimidad del gobierno en turno, mediante la distribución de los beneficios entre los grupos pobres, desde las formas clientelistas y corporativas tutoras de la ciudadanía. Estas formas, en principio, no se contraponen a las redes solidarias o de autoayuda establecidas por los migrantes. No obstante, a partir del segundo lustro de la década de los setenta, fue evidente que la estructura corporativa significaba un costo excesivo para el Estado, pues por un lado, la carga de clientelismo, de dominación tradicional y de corrupción impedía la distribución equitativa de los beneficios y el cumplimiento de los objetivos justicialistas de la política social de los regímenes poscardenistas. Por otro lado, la complejidad de los nuevos procesos sociales (imputables al crecimiento industrial, comercial y financiero y a las nuevas valoraciones culturales que recorrían el mundo en la década de lossesenta), habían producido una exclusión de grandes grupos de migrantes y de nuevos grupos urbanos, de dichos beneficios.

Para el Estado los costos excesivos significaron, con algunas oscilaciones que tuvieron como fin preservar el sentido de justicia social, el acotamiento y desmantelamiento en algunos casos del aparato institucional encargado de difundir y distribuir los beneficios. Este proceso, que se inicia en los primeros años de la década de los ochenta, se ha mantenido como el proyecto estatal durante los últimos tres regíme- nes. Una de las hipótesis por explorar en este periodo, que empieza en el último lustro de la década de los setenta, es el debilitamiento de las formas tradicionales de legitimidad, que habían sustentado las estructuras estatales, como producto de la retirada del Estado de amplias esferas del bienestar social. Desde el primer lustro de la década de los ochenta, se advierte una tendencia al crecimiento de movimientos sociales independientes y de ciudadanización de las organizaciones conforme se opera un retiro del Estado. Al mismo tiempo, el Estado impulsa formas de "corresponsabilidad" con las organizaciones sociales a través de programas de abasto y vivienda. Estas formas pretenden involucrar a las organizaciones sociales en la creación de los programasy en la distribución de los beneficios. Ejemplos de estas políticas sociales son el abasto a zonas urbanas marginadas (conocido como PAZPU, por sus siglas) y el programa de vivienda para sectores urbanos populares operado por el Fondo Nacional de Habitaciones Populares (Fonhapo), am. bos desarrollados durante el gobierno de De la Madrid. ${ }^{7}$

La respuesta oficial a la crisis de legitimidad en la segunda mitad de la década pasada no consistió, sin embargo, en recorporativizar los movimientos en el partido oficial. Por el contrario, para paliar la díficil situación, se

7 Cuestión que se debió en parte, como ha apuntado Fox, a la herencia de las tradiciones reformistas de los funcionarios herederos de los movimientos del año 68 incorporados al apara. to gubernamental, y a la presión que desde abajo ejercían los movimientos sociales. Véase: Fox, "Targeting", 1994, pp. 179-216. 


\section{SECUENCIA}

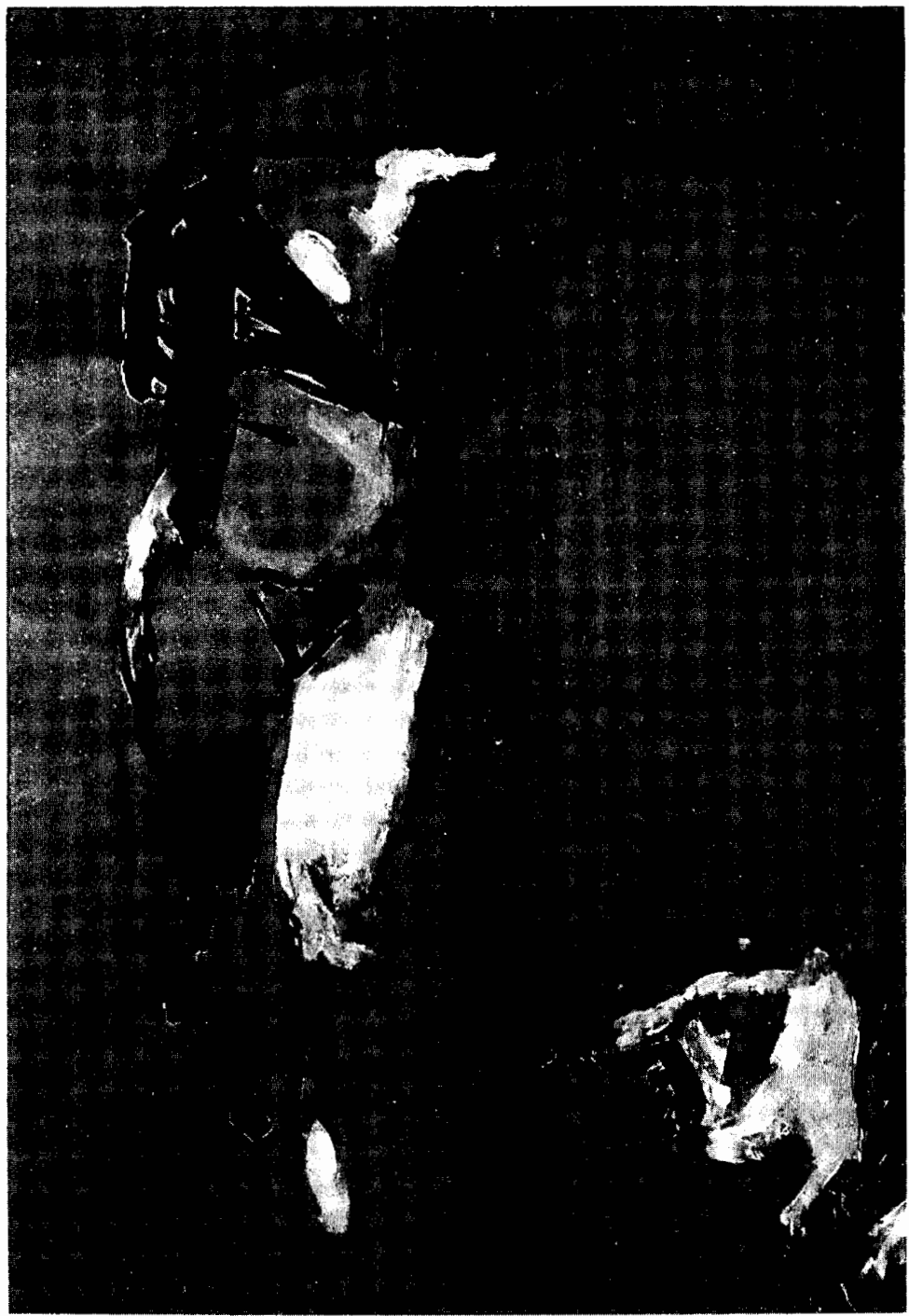

Ilustraciones de Sandra Pani. Queda estrictamente prohibida la reproducción total o parcial de las imágenes publicadas en este número de la revista Secuencia, 37.

Las imágenes fueron contratadas y/o donadas de forma exclusiva para esta publicación. 
aprovechó la gran oportunidad que representaban los movimientos ya consolidados de los ochenta, uno de cuyos múltiples orígenes - pero no menos importante- fueron las experiencias de organización social tradicional, de formación de liderazgos, de trabajo comunitario, de solidaridad, etc. El aprendizaje del movimiento urbano popular en la lucha desde los años setenta, se aprovechó como un recurso importante en la operación de los programas sociales, como se ha dicho, para ahorrar recursos en un contexto de aguda crisis fiscal del Estado.

La novedad de la política social salinista fue que las tendencias a la restructuración de la legitimidad mediante la corresponsabilidad entre organización social y gobierno, a través del Programa Nacional de Solidaridad (Pronasol), estuvieron bajo el control presidencial. Si bien el liderazgo centralizado del presidente contribuyó a una mayor eficiencia en el manejo de los recursos y a eliminar trabas burocráticas importantes, además de un cierto reconocimiento del valor de la organización social, por otro lado reforzó la institución presidencial y la centralización del poder. La imagen y el prestigio presidencial alcanzaron niveles muy altos entre los grupos pobres. A esto contribuyó no sólo la distribución de los beneficios, sino el gran aparato comunicativo puesto al servicio de este programa. Es significativo que las opiniones de los grupos pobres, incluso de aquellas personas que no habían recibido los beneficios de Pronasol, fueran altamente favorables sobre el programa y la figura presidencial. Estas opiniones coincidian con una fuerte identidad respecto a los liderazgos de las organizaciones, marcados estos últimos por una centralización de los recursos y de la toma de decisiones.

Una de las probables explicaciones a esta simbiosis entre autoritarismo y centralización presidencial, por un lado, y centralización de recursos y gestiones al nivel de las organizaciones sociales, por otro, es atender la formación de la cultura autoritaria, fenómeno estudiado por la escuela de Frankfurt. Pero la explicación puede enriquecerse por la recuperación de las formas de trabajo colectivo, el establecimiento de redes de solidaridad y la consolidación de liderazgos a través de estas acciones. De tal modo que la legitimidad de las acciones de liderazgo y las gubernamentales se desenvuelve en la formación y estructuración de identidades que se fundamentan en los procesos de socialización, de cooperación y de trabajo colectivo. Sin embargo, contradictoriamente, en un proceso extremadamente complejo, estas formas originan los autoritarismos y la gestión democrática y colectiva.

En qué medida el estudio de esta simbiosis y de las actitudes respecto a la autoridad y a la democracia es importante para el examen de las organizaciones sociales y de la política social, es el tema siguiente.

\section{RASGOS DE LA CULTURA POLÍtica EN ORGANIZACIONES POPULARES}

En la investigación desarrollada pudimos observar características de la cultura política considerando dos tipos de organizaciones sociales, identifica- 
das por su origen con el movimiento urbano popular, aunque con distinta orientación: una organización de in quilinos y otra de solicitantes de vivienda en la zona conurbada.

La primera, Campamentos Unidos (CU), se ubica en el centro de la ciudad de México. Se formó a partir de los sismos de 1985 y está integrada por antiguos inquilinos de la zona; se trata de sectores de bajos recursos, cuya principal opción habitacional han sido las vecindades en las cuales familias de trabajadores, de un promedio de cinco o más miembros, vivían generalmente en un solo cuarto. El deterioro en que se encontraban por falta de mantenimiento provocó que los sismos de septiembre de aquel año produjeran graves daños en esas viviendas y quedaran sin casa miles de familias. Los conflictos entre propietarios e inquilinos llevaron a que el gobierno federal decretara la expropiación de alrededor de 4000 predios, en toda la zona destruida, entre los cuales se localizaban las viviendas de la colonia Guerrero. ${ }^{8}$

CU es una organización popular caracterizada por un liderazgo con una fuerte centralización de las decisiones. Esto ha permitido a los líderes un amplio control sobre las vecindades reconstruidas y la preservación de las viviendas respecto del mercado, evitando su venta, traspaso o renta; han contado además con una amplia gama de fuentes de financiamiento; 9 con

${ }^{8}$ Ziccardi, "Política", 1986, p.129.

${ }^{9}$ Como la Federación Internacional de Futbol Asociación (FIFA), sindicados de obreros suizos y alemanes, Cruz Roja y el Departamento del Distrito Federal (DDF).

CULTURA POLITICA Y POBREZA URBANA estos recursos han construido aproximadamente 250 viviendas agrupadas en 19 vecindades y tienen planeado construir más para los hogares damnificados por los sismos que aún viven en campamentos. La disponibilidad de fondos les ha permitido una relativa independencia respecto a los programas y subsidios gubernamentales. Los representantes de cu han manifestado que no tienen interés en participar en el sistema de partidos políticos, sin embargo, de una actitud crítica hacia el PRI han pasado a un acercamiento. El papel de este partido dentro de la organización constituye un elemento mediador en la formación de la cultura política de los miembros de la organización. Esta situación se relaciona con el nivel de eficiencia técnica y administrativa que han logrado sus dirigentes.

La eficiencia del liderazgo ha posibilitado llevar a cabo proyectos de viviendas amplias, funcionales y con un diseño que supera ampliamente a los programas oficiales, sin afectar el concepto de espacio colectivo típico de las antiguas vecindades. ${ }^{10}$ Finalmente, también han conseguido preservar la identidad de barrio y organizativa de estos habitantes del centro de la ciudad, apoyados en su voluntad expresa de seguir viviendo en las casas en las que muchos de ellos nacieron. ${ }^{11}$

${ }^{10}$ El nuevo diseño eliminó fuentes de conflicto como los baños y lavaderos comunes; ahora cada vivienda cuenta con estos servicios.

${ }^{11}$ El reforzamiento de la identidad se expresa culturalmente en el hecho de que toda vecindad cuenta con murales y esculturas de Daniel Manrique. 
El éxito de los proyectos ha redun. dado en un fuerte control y en centralización de la dirección, manifestados en primer lugar en la prohibición expresa de introducir las viviendas al mercado. El alto grado de identificación con la organización y la opinión favorable sobre los dirigentes sugieren un liderazgo personalista. Sin embargo, en el estado actual de nuestra investigación es necesario profundizar en el análisis para conocer el nivel de participación consensual y su relación con la cultura política mexicana. Tentativamente podemos establecer que existe una triple coincidencia con los rasgos de la cultura política que hemos definido más arriba: ei grado de centralización del liderazgo; su alto nivel de eficiencia, y reforzamiento de los mecanismos de identidad.

A diferencia de la anterior, la otra organización seleccionada, Unión de Colonias Populares (UCP), ubicada en Ecatepec, no tiene un control exclusivo sobre el predio, pues existen otras organizaciones que constituyen un amplio espectro, tales como Asamblea de Barrios, Movimiento Popular Independiente y algunas pertenecientes al PRI. Nuestra investigación demostró que la UCP era la más fuerte por el mayor número de pobladores identificados con ella. Probablemente influya el hecho de que los comerciantes de dos mercados en esta zona, conocida como Los Polígonos, están afiliados a esta organización.

Sus características son un menor grado de centralización de la autoridad del liderazgo; un bajo nivel de participación e identificación de los miembros con la organización, y un alto grado de comercialización de las viviendas subsidiadas por parte de los beneficiarios, siendo frecuentes el traspaso, la renta y la venta. A diferencia de los habitantes del centro de la ciudad, los pobladores no están arraigados en el espacio urbano habitado. Se vincularon a la organización por el interés común de obtener una vivienda y procedian sobre todo de los municipios conurbados y de diversas partes del Distrito Federal. Consiguieron suelo por medio de una invasión al predio que ahora ocupan, la cual fue reprimida, sin embargo posteriormente, a través de una negociación las autorida. des tramitaron la expropiación del terreno y mediante un programa de vivienda de FONHAPO se construyeron y se otorgaron aproximadamente 5200 viviendas. Las metas de la organización se vinculan a demandas de carácter político más amplias identificadas con el Movimiento Urbano Popular de la década de los setenta, basado en la ideología de línea de masas de orientación maoísta, cuya estrategia de lucha se relaciona estrechamente con otros grupos opositores denominados de izquierda en aquella época. ${ }^{12}$

Actualmente la UCP tiene relación con el Partido de la Revolución Demo-

12 Sus objetivos fueron sintetizados durante elIV Encuentro Nacional de la CONAMUP: 1.Crear una organización amplia y única del sector popular independiente. 2 . Impulsar la creación de un frente nacional, en el que paticipen todos los sectores del pueblo explotado y oprimido de México, y 3. Luchar por la destrucción de la sociedad capitalista pormedio de la tranformación revolucionaria hasta la toma del poder político y la creación de una sociedad sin clases. Véase: Ramírez, "Proyecto”, 1986, pp. 38-43. 
crática, aunque la filiación a este partido de los miembros de la organización no es abiertamente forzosa.

No obstante que la UCP y otras organizaciones que tienen presencia en el predio no son afines al partido oficial, con la obvia excepción de las pertenecientes al PRI, llama la atención que sus agremiados expresen una buena opinión sobre el presidente y su programa de política social.

Aquí el liderazgo ha funcionado de manera centralizada aunque tiende a desplazarse de la vivienda al abasto. La incapacidad de impedir la incorporación de las viviendas al mercado ha debilitado la dirección en la zona. No obstante, el control sobre los comerciantes del mercado público es muy fuerte. Esto garantiza su permanencia como organización en la zona. ${ }^{13}$

\section{OPINIONES Y CULTURA POLÍTICA EN SECTORES URBANOS POBRES}

Las opiniones de los grupos pobres de la ciudad de México y de la Zona Metropolitana de la Ciudad de México (ZMCM) fueron recabadas como parte de una encuesta diseñada para conocer las relaciones entre hogares y organizaciones respecto al acceso a los satisfactores básicos, de vivienda y ali-

${ }^{13} \mathrm{La}$ UCP es una organización presente en catorce municipios del estado de México, Michoacán, Jalisco, Tepic, Chiapas y Querétaro. Perteneció a la Coordinadora Nacional del Movimiento Urbano Popular Conamup hasta 1984. Frente Metropolitano en 1987 y fundadora de la Convención Nacional Urbano Popular en 1989. Esteve, Movimientos, 1992, p.119. mentación. ${ }^{14}$ La encuesta consta de 429 entrevistas a hogares, con un registro total de 2170 individuos. 15

Entre las preguntas que se diseñaron para conocer las opiniones destacan las relativas al origen de los subsidios, la pertenencia a la organización y la opinión de los entrevistados acerca de las autoridades tanto locales como federales.

En relación con los subsidios alimen. ticios, sobresale la idea de que es Solidaridad quien los otorga, entre $23.6 \%$ de los entrevistados. Sin embargo, la ignorancia respecto al origen del subsidio es también muy alta. De hecho se equipara con aquellos que piensan que los subsidios alimenticios son dados por el presidente de la república. La Compañía Nacional de Subsistencias Populares (Conasupo), que institucionalmente se encarga de la distribución de los beneficios en leche y tortilla se encuentra en una cuarta posición, lo que habla de una pérdida en su imagen institucional, sustituida en las percepciones y evaluaciones populares, por el programa presidencial.

De acuerdo con los objetivos de la investigación, con los datos recolectados se construyó la variable de tipos de acceso que reúnen los hogares que

${ }^{14}$ Los temas que aborda son: vivienda: calidad, financiamiento, subsidios y equipamiento, empleo, ingreso y gasto familiar; alimentación: calidad, impacto de los subsidios alimenticios en el ingreso familiar y otras formas de abasto; pertenencia de los agremiados a la organización, y algunas opiniones políticas. El trabajo de campo fue realizado durante julio de 1993.

15 El levantamiento se basó en un muestreo sistemático del $6 \%$ de las viviendas habitadas en Ecatepec y cerca de $30 \%$ en la colonia Guerrero. 
poseen el suelo, la vivienda y tienen acceso a los programas sociales de abasto. Los hogares beneficiarios de vivienda, terreno y programas sociales de abasto de leche y tortilla, ya sea a ambos o a uno solo de estos últimos, los agrupamos en el tipo de acceso 1 . Los hogares que sólo se benefician del acceso al suelo y a la vivienda, los reunimos en el tipo 2. Finalmente, los que carecen de acceso a todos estos servicios, los agrupamos en el tipo 30 acceso subsidiado nulo. Este último tipo de hogares corresponde a aquellos que han adquirido la vivienda por traspaso, la han compradó o la ocupan en alquiler. Este tipo de hogares se ubica exclusivamente en la zona de Ecatepec, por el proceso de incorporación de la vivienda al mercado, que ya ha sido explicado más arriba.

Los accesos al suelo, a la vivienda y a los programas alimenticios mediante la intervención del Estado o la gestión de las organizaciones sociales en la satisfacción de algunas necesidades básicas, puede constituirse en una variable explicativa de las creencias de legitimidad de la personalidad presidencial, de sus programas de política social, de los procesos electorales y de la confianza en los líderes, así como de la identidad que los entrevistados y sus familias tienen con las organizaciones a través de las cuales consiguieron la vivienda. No pretendemos establecer con ello una visión determinista de la cultura política desde variables economicistas. Por el contrario, queremos destacar la importancia de la gestión social, que incluye asistir a juntas, plantones, realizar marchas y movilizaciones, tomas de oficinas pú- blicas, redacción de oficios, trámites burocráticos, etc., para lograr el acceso a diferentes servicios. Todas estas experiencias son un acervo organizativo que se integra a un proceso de socialización entre los grupos pobres y se incorpora como parte fundamental en la construcción de las creencias, percepciones y evaluaciones del sistema político, a diferencia de los enfoques que actualmente predominan y que ven las opiniones políticas como un momento aislado, limitadas al voto electoral, y que no toman en cuenta estos procesos de formación de identidades. La lucha por los accesos incluye la formación de un sentido de pertenencia e identidad entre los participantes. El tiempo de permanencia en las organizaciones se relaciona con la capacidad de éstas para formular nuevos proyectos, ampliar su base socialy diversificar sus demandas, pero también para reforzar la autoestima y el sentimiento de pertenencia e identidad entre sus miembros. Este reforzamiento puede ser una eficaz defensa en contra de los intentos de suplantar a organizaciones por medio de la construcción de la política social.

Las tendencias que se advierten señalan a los procesos de mercantilización de los bienes obtenidos a través de la organización, como un factor significativo que requiere ser estudiado con mayor profundidad en relación con su fortalecimiento como forma de mediación y de control de la eficacia de la política social. En relación con la calidad de los bienes que gestionan, ${ }^{16}$

16 En la colonia Guerrero las viviendan cuentan con $90 \mathrm{~m}^{2}$ en promedio de construcción, a 
las clientelas tradicionales de las organizaciones sociales tienden a separarse de éstas y a perder identidad en la medida que alcanzan los objetivos iniciales, tales como el suelo y la vivienda. En este sentido la hipótesis individualista parece tener cierto grado de pertinencia, ${ }^{17}$ que no obstante, puede ceder su sitio en la medida que se incrementan los mecanismos de reforzamiento de la identidad y la capacidad de la organización para generar nuevos proyectos y demandas, los cuales son la base de la cultura de la gestión social en los miembros de los hogares.

Entre las preguntas que se diseñaron para conocer las opiniones, destacan el origen de los subsidios, el sentido de pertenencia a la organización, la opinión de los entrevistados acerca de sus autoridades, confianza en sus líderes y opinión sobre el Pronasol.

La fuerza del presidencialismo entre los grupos pobres se refleja en sus opiniones favorables sobre el presi. dente y el Pronasol. Sobre el origen de los subsidios alimenticios, sobresale la creencia de que son Solidaridad y el presidente quienes los otorgan. Los resultados muestran que existe una opinión favorable sobre los líderes de las organizaciones. El poder local se encuentra más desfavorecido en las opiniones populares, al igual que la confianza en las elecciones. El sentido de militancia y pertenencia a las orga-

diferencia de la zona de Los Polígonos en Ecatepec, donde Fonhapo entregó casas de $18 \mathrm{~m}^{2}$, aunque bajo el concepto de vivienda progresiva.

${ }^{17}$ Olson, Logic, 1971. nizaciones es bajo, aún cuando los beneficiarios de tipo 2 tienen un sentido de pertenencia más arraigado, por las expectativas en relación con el suelo y la vivienda.

Sobre el origen de los subsidios, la opinión favorable en torno al presidente y al Pronasol, destaca entre los beneficiarios de tipo 1 y 2 . Sin embargo, la ignorancia respecto al origen del subsidio es también muy alta entre los beneficiarios de tipo 2 y 3 . De hecho se equipara con aquellos que piensan que los subsidios alimenticios son dados por el presidente de la república. Conasupo, que institucionalmente se encarga de la distribución de los beneficios en leche y tortilla está en cuarta posición, lo que habla de una merma en su imagen institucional, sustituida por el programa presidencial en las percepciones y evaluaciones populares, como puede verse en el cuadro 1 .

La opinión sobre el presidente de la república tiende a ser más alta conforme se goza de un mayor acceso a los subsidios en suelo, vivienda y alimentos. Como puede observarse, la proporción de beneficiarios de tipos 1 y 2 que tienen buena opinión de la gestión presidencial, es mayor que entre quienes no tienen acceso a estos subsidios. Esta misma tendencia se advierte en la opinión sobre el Pronasol. A un mayor acceso es mejor la opinión, aunque entre los hogares de tipo 3 la opinión también es relativamente alta. $67.6 \%$ del tipo 1 y $66.8 \%$ del tipo 2 tienen buena opinión de Pronasol. En el tipo 3 esta misma opinión sólo la tienen el 50 por ciento de los pertenecientes a este grupo.

Respecto a las autoridades locales, 
en el caso de Ecatepec la tendencia a una opinión regular y mala es mucho más alta que la opinión en este sentido sobre las autoridades federales. Además de que crece la proporción de quienes se abstienen de expresar su opinión sobre las instituciones del poder local, presidencia municipal y gobierno del estado. Estos resultados muestran una proclividad a creer en una mayor legitimidad del poder central y capacidad de resolución de carencias, frente a los poderes locales, al menos en estos sectores urbanos de la zona metropolitana de la ciudad de México.

La identificación con la organización es baja, sólo $31.5 \%$ de los entrevistados declaró pertenecer a alguna organización y de éstos, $60 \%$ se encuentran en Campamentos Unidos. Una probable explicación de este hecho puede encontrarse en los mecanismos de integración comunitaria y de identificación con la dirección de la organización que fueron mencionados más arriba.

Es probable que la pertenencia dependa por una parte de los objetivos alcanzados por la organización y por otra, de las expectativas de los asociados. La identificación de los asociados es mayor entre los beneficiarios de tipo 2 que entre aquellos que ya obtuvieron suelo, vivienda y acceso a algún programa de leche y tortilla o a ambos. Una situación de carencia puede reflejar un escaso interés en participar. Entre los que declararon pertenecer a alguna organización sólo $8.2 \%$ pertenecen a los hogares del tipo 3.

Las anteriores observaciones coinciden con la permanencia en la organiza- ción social. Como puede observarse el éxodo de asociados de las organizaciones y la pérdida del sentido de pertenencia a las mismas, son muy altos. Esto puede relacionarse con el grado de clientelismo de las organizaciones. Entendemos por clientelismo, la pertenencia a las organizaciones bajo la expectativa de satisfacer una demanda. Esto es, que el asociado se identifica con la organización no sólo por una convicción ideológica, sino por la esperanza de satisfacer sus necesidades. Para mantener con vida a las organizaciones, deben generarse nuevas demandas que perpetúen la relación social líderes-asociados. Cuando eso no es posible, los asociados se identifican cada vez menos con la organización.

De nuestra muestra, 358 entrevistados declararon haber obtenido sus viviendas a través de alguna organización social. Las más importantes en cuanto a gestión habían sido Campamentos Unidos y Unión de Colonias Populares. No obstante, la UCP había disminuido su peso relativo. De $25.4 \%$ de los entrevistados que declararon haber obtenido su vivienda a través de esta organización, sólo $15 \%$ declararon seguir perteneciendo a la misma. En CU, aunque formalmente todos los entrevistados pertenecen a la organización, $79 \%$ se deciaró identificado con ella, siendo en la actualidad la de mayor afiliación relativa, con casi $60 \%$ de los que declararon pertenecer a alguna organización. El PRI tiene una caída más severa, pues de $15 \%$ de entrevistados que obtuvieron su vivienda a través de este partido, sólo $3.8 \%$ declararon su identificación actual con 


\section{Cuadro 1. Tipo de acceso y opiniones*} (porcentaje)

\begin{tabular}{|c|c|c|c|c|c|c|}
\hline Opiniones & Tipo 1 & & po 2 & & ipo 3 & \\
\hline $\begin{array}{l}\text { Quién otorga los } \\
\text { subsidios alimenticios }\end{array}$ & $\begin{array}{l}\text { Pronasol } \\
\text { Conasupo } \\
\text { presidente }\end{array}$ & $\begin{array}{l}23.6 \\
22.1 \\
21.4\end{array}$ & $\begin{array}{l}\text { Pronasol } \\
\text { presidente } \\
\text { Conasupo }\end{array}$ & $\begin{array}{l}24.7 \\
18.8 \\
12.6\end{array}$ & $\begin{array}{l}\text { Pronasol } \\
\text { Conasupo } \\
\text { presidente }\end{array}$ & $\begin{array}{l}21.9 \\
21.9 \\
18.8\end{array}$ \\
\hline Presidente & $\begin{array}{l}\text { buena } \\
\text { regular }\end{array}$ & $\begin{array}{l}57.0 \\
23.9\end{array}$ & $\begin{array}{l}\text { buena } \\
\text { regular }\end{array}$ & $\begin{array}{l}55.7 \\
27.7\end{array}$ & $\begin{array}{l}\text { buena } \\
\text { regular }\end{array}$ & $\begin{array}{l}44.1 \\
35.8\end{array}$ \\
\hline Pronasol & buena & 67.6 & buena & 66.8 & buena & 50.0 \\
\hline $\begin{array}{l}\text { Autoridades } \\
\text { municipales }\end{array}$ & $\begin{array}{l}\text { buena } \\
\text { regular } \\
\text { mala }\end{array}$ & $\begin{array}{l}17.5 \\
36.7 \\
30.0\end{array}$ & $\begin{array}{l}\text { buena } \\
\text { regular } \\
\text { mala }\end{array}$ & $\begin{array}{l}15.7 \\
35.8 \\
27.6\end{array}$ & $\begin{array}{l}\text { buena } \\
\text { regular } \\
\text { mala }\end{array}$ & $\begin{array}{r}4.3 \\
34.6 \\
30.4\end{array}$ \\
\hline $\begin{array}{l}\text { Autoridades } \\
\text { estatales }\end{array}$ & $\begin{array}{l}\text { buena } \\
\text { regular } \\
\text { mala }\end{array}$ & $\begin{array}{l}16.7 \\
35.8 \\
27.5\end{array}$ & $\begin{array}{l}\text { buena } \\
\text { regular } \\
\text { mala }\end{array}$ & $\begin{array}{l}13.0 \\
41.1 \\
20.5\end{array}$ & $\begin{array}{l}\text { buena } \\
\text { regular } \\
\text { mala }\end{array}$ & $\begin{array}{r}8.7 \\
39.1 \\
30.4\end{array}$ \\
\hline $\begin{array}{l}\text { Pertenencia } \\
\text { a organizaciones }\end{array}$ & $\begin{array}{l}\text { sí } \\
\text { no }\end{array}$ & $\begin{array}{l}25.7 \\
74.3\end{array}$ & $\begin{array}{l}\text { sí } \\
\text { no }\end{array}$ & $\begin{array}{l}34.7 \\
65.3\end{array}$ & $\begin{array}{l}\text { sí } \\
\text { no }\end{array}$ & $\begin{array}{l}32.4 \\
67.6\end{array}$ \\
\hline $\begin{array}{l}\text { Organización de } \\
\text { pertenencia }^{* * *}\end{array}$ & $\begin{array}{l}\text { CU } \\
\text { UCP } \\
\text { PRI }\end{array}$ & $\begin{array}{r}47.2 \\
19.4 \\
8.3\end{array}$ & $\begin{array}{l}\text { CU } \\
\text { UCP } \\
\text { PRI }\end{array}$ & $\begin{array}{r}64.0 \\
16.3 \\
2.3\end{array}$ & $\begin{array}{l}\text { CU } \\
\text { UCP } \\
\text { PRI }\end{array}$ & $\begin{array}{r}63.6 \\
0.0 \\
0.0\end{array}$ \\
\hline $\begin{array}{l}\text { Integración a la } \\
\text { organización }\end{array}$ & $\begin{array}{l}\text { familiares } \\
\text { amigos } \\
\text { vecinos }\end{array}$ & $\begin{array}{l}35.2 \\
32.8 \\
17.6\end{array}$ & $\begin{array}{l}\text { familiares } \\
\text { amigos } \\
\text { vecinos }\end{array}$ & $\begin{array}{l}32.7 \\
19.5 \\
36.6\end{array}$ & $\begin{array}{l}\text { familiares } \\
\text { amigos } \\
\text { vecinos }\end{array}$ & $\begin{array}{l}47.1 \\
17.6 \\
35.3\end{array}$ \\
\hline $\begin{array}{l}\text { Confianza en } \\
\text { lideres }\end{array}$ & $\begin{array}{l}\text { sí } \\
\text { no }\end{array}$ & $\begin{array}{l}47.2 \\
43.7\end{array}$ & $\begin{array}{l}\text { sí } \\
\text { no }\end{array}$ & $\begin{array}{l}45.5 \\
43.5\end{array}$ & $\begin{array}{l}\text { sí } \\
\text { no }\end{array}$ & $\begin{array}{l}32.4 \\
61.8\end{array}$ \\
\hline $\begin{array}{l}\text { Confianza en } \\
\text { elecciones }\end{array}$ & $\begin{array}{l}\text { sí } \\
\text { no }\end{array}$ & $\begin{array}{l}47.2 \\
43.7\end{array}$ & $\begin{array}{l}\text { sí } \\
\text { no }\end{array}$ & $\begin{array}{l}45.5 \\
43.5\end{array}$ & $\begin{array}{l}\text { si } \\
\text { no }\end{array}$ & $\begin{array}{l}32.4 \\
61.8\end{array}$ \\
\hline
\end{tabular}




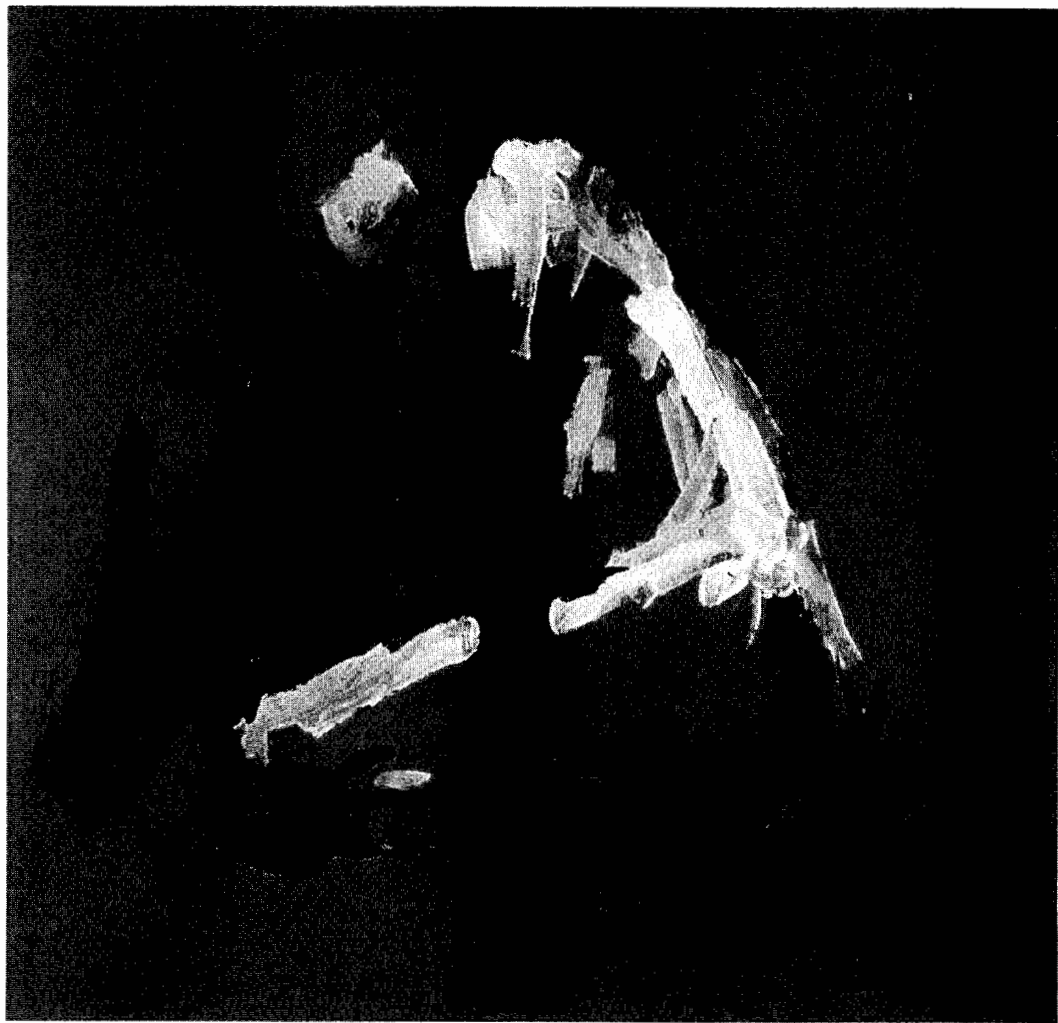

él. Las redes de solidaridad familiar y amistosa juegan un papel fundamental en la consecusión de los accesos. Las relaciones de trabajo y otras formas de socialización, como los medios de comunicación, tienen un peso específico menor. Las formas de integración a las organizaciones para la gestión de los diversos accesos se llevan a cabo por medio de lazos familia- res, con las redes de información y de solidaridad que en su seno establecen sus miembros. Los vecinos y los amigos también constituyen un medio significativo en el establecimiento de vínculos con la organización y de apoyo mutuo para su ingreso.

Los niveles de confianza en los líderes de las organizaciones y en las elecciones tienden a aumentar conforme 
se tiene un mayor acceso y las expectativas se han cumplido. El nivel de desconfianza es mayor entre los hogares de tipo 3 en ambos casos, lo cual sugiere una relación condicionada entre la confianza en los líderes y los procesos electorales, y el cumplimiento de las expectativas y de las demandas entre los grupos pobres.

\section{A MANERA DE CONCLUSIONES}

El concepto de cultura política de los grupos pobres urbanos debería formarse no sólo en relación con las evaluaciones y percepciones sobre el sistema político, como supondría un concepto tradicional de cultura política que opera bajo el supuesto de una cultura cívica extraña o por lo menos alejada de la satisfacción de las necesidades básicas, sino en relación con los accesos relacionados con la satisfacción de éstas. La organización de los grupos pobres y las experiencias de socialización que viven en la formulación de demandas, en la redacción de un oficio petitorio, en la negociación con los burócratas, en la toma de oficinas y en la participación en una marcha o manifestación son experiencias que configuran la identidad y las creencias de legitimidad frente al sistema político. No obstante, estas experiencias de socialización no han desplazado la fuerza de la imagen presidencial.

A pesar de los logros de estos grupos a través de su propia gestión o de sus organizaciones, los atribuyen en una proporción importante al poder presidencial o a la política social vigente. Las creencias de legitimidad entre los grupos pobres son más fuertes respecto al presidente que respecto a las autoridades locales más cercanas. Esto refuerza tanto la centralización del poder como la atribución de mayor eficiencia al presidente de la repú. blica, en comparación con las instancias locales del sistema político. Esta situación retrasa el desarrollo de una cultura democrática y participativa, pero el persistente peso histórico del presidencialismo en el régimen político mexicano, es ciertamente un factor indispensable para la puesta en marcha de la política social.

Las organizaciones, por su parte, con los liderazgos centralizados tienden a reproducir este dualismo con menor o mayor éxito, lo cual determina el grado de identidad de los asociados o su alejamiento de la organización, en la medida en que ésta no es capaz de generar nuevas demandas. Con todo, las organizaciones sociales han demostrado ser un canal eficiente para el acceso al suelo, la vivienda y los programas sociales de abasto para los grupos pobres. Además, han contribuido al fortalecimiento de los lazos de solidaridad y el establecimiento de las redes de comunicación para una mayor satisfacción de las necesidades básicas. Los procesos de gestión que han experimentado los grupos pobres urbanos, sobre todo a partir de la década pasada, pueden ser el origen de una nueva cultura política más participativa y más propositiva, a condición de fomentar una cultura ciudadana alejada de formas tulelares tradicionales, además de que requiere ser estimulada y puesta en práctica desde los espacios locales. Así, la gestión de la política 
social y sus relaciones con las demandas de democratización, llevan a formular prguntas sobre las tendencias actuales de la política social, las cuales obligan a realizar un urgente esfuerzo no sólo analítico, sino político. Particularmente a la luz de la anunciada Alianza para el Bienestar y la descentralización del gasto social, entre otras medidas, hoy habria que preguntarse: ¿hasta qué punto la política social zedillista se perfila como un programa sexenal y personalista más? Y frente a la tradición de politización de la política social y los rasgos caciquiles del poder local en el interior del país: ¿cuáles son las ventajas de la propuesta de federalización y cuáles sus desventajas? Asimismo, en el marco de la baja generalizada en los niveles de vida y la profundización de la pobreza: ¿cuáles son los rubros prioritarios de la "nueva política social"? Finalmente, ¿es posible pensar que la fomentada "corresponsabilidad" de la sociedad para el bienestar, esconde una forma más de ciudadanía tutelada o dirigida?

\section{BIBLIOGRAFIA}

-Almond, Gabriel y Sidney Verba, The civic culture. Political attitudes and democracy in five nations, Princeton, Nueva Jersey, 1963.

, The civic culture revisited, Little Brown and Co., Princeton, Nueva Jersey, 1980.

Cornelius, Wayne y Ann Craig, Los migrantes pobres en la ciudad de México y la política, FCE, México, 1980.
-Eckstein, Susan, El Estado y la pobreza urbana en México, Siglo XXI, México, 1982.

-Esteve Díaz, Hugo (coord.), Los movtmientos sociales urbanos. Un reto para la modernización, IPE, México, 1992.

-Fox, Jonathan, "Targeting the poorest: The role of national indigenous Institute in Mexico's Solidarity program", en Wayne A. Cornelius et al., Transforming statesociety relations in Mexico, The national solidarity strategy, Center for U.S.Mexican Studies-University of California, San Diego, 1994.

-Guadarrama, Rocío, "Democracia y cambio político: recuento y reactualización del debate sobre la cultura política", Polis 93. Anuario de Sociología, UAM-I, México, 1994.

-Gutiérrez, Alonso, "Algunas aportaciones recientes para el estudio de la cultura política en México" en S. Héctor Rosales Ayala, Cultura, cultura política e investigación urbana, CRIM-UNAM, México, 1990.

-Lomnitz, Larissa Adler de, Cómo sobreviven los marginados, Siglo XXI, México, 1977.

-Melucci, Alberto, "Liberation or meaning? Social movements, culture and democracy", Development and change, núm. 3, 1992.

-Olson, Mancur, The logic of collective action, public goods and the theory of groups, Schocken books, Nueva York, 1971.

-Ramírez Sáiz, Juan Manuel "El proyecto de masas de la CONAMUP: balance provisional", Estudios políticos, Nueva época, vols. 4-5, núms. 4-1, octubre, 1985-marzo, 1986.

-Ziccardi, Alicia, "Política de vivienda para un espacio destruido", Revista Mexicana de Sociología, año XLVIII, núm. 2, abril-junio, 1986. 